\title{
IMPORTANCE OF DIFFUSION PUMPING WHILE PRODUCING AMORPHOUS AND PARTIALLY CRYSTALLISED MATERIALS
}

\author{
Marcin NABIAŁEK ${ }^{1}$, Bartosz PŁOSZAJ ${ }^{1, *}$ \\ ${ }^{1}$ Chair of Physics, Faculty of Production Engineering and Materials Technology, \\ Czestochowa University of Technology, 19 Armii Krajowej Str., 42-200 Częstochowa, Poland
}

\begin{abstract}
It can be state that 1960 was the year when amorphous materials era began. 1989 was the year when bulk materials amorphous were first produced. Since then researchers around the World try to improve or find new correlations according to this group of materials. Sometimes instead of obtaining amorphous materials produced sample may be partially crystallised. During last research, ingots of two different alloys discussed in this work were produced with and without use of diffusion pump. Samples produced in injection method were done under the same condition for both cases of ingots. Then samples were subjected to structure analysis with the use of $x$-rays and were checked according to magnetic properties. Obtained results are compatible with expectations, however by meet one give promising possibility of further research.
\end{abstract}

Keywords: soft magnetic alloys, amorphous materials, partially crystallised materials, $x$-ray diffractometry, magnetic properties.

\section{Introduction}

A structure with long-range atomic disorder may be obtained, when sufficiently high cooling rates are available during production alloy, hence crystallization process is stopped while alloy solidification process. From the literature it is known that first amorphous alloys were produced in 1950s and 1960s [1]. Till 1989 when A. Inoue of the University of Tohoku, and his colleagues presented principles which enable to produce materials exceeding limited thickness of $100 \mu \mathrm{m}$, amorphous materials were studied intensively and different methods of production and compositions were proposed. This decisive year was a point from which it can be state that bulk amorphous era had begun [2-4]. Proper selection of alloying constituents allows many chemical compositions to obtain disordered structure. Alloys with the Fe and Co as the base constituents are considered as important sub-group of amorphous representatives [5-6]. Magnetic properties of such sub-group often are better in according to their crystalline counterparts. However, partial crystallization of amorphous alloys may improve magnetic properties even better according to amorphous materials without partial crystallization. It should be notice that partial crystallization is difficult to obtain as well as time consuming. Typical process considered heat treatment of the alloys. But there is possibility to obtain partially crystalized alloys in single-step production process. Proper selection of alloying constituent together with appropriate production parameters allows to obtain demanded crystalline phases and magnetic properties. From the theoretical backgrounds activation energy of crystallization is crucial. Such large amount of energy when provided to the amorphous alloy, result in tendency of forming crystal seeds within the volume 
of the material. Later on, it leads in their growth till the formation of crystallites with nanometric sizes. Modern functional alloys, including ones with amorphous and nanocrystalline structure, have wide range of possible applications. Very good magnetic characteristics are observed for materials amorphous and nanocrystalline structure. As the result such materials may be applied in transformers, electric motors or even in microgenerators [7-10].

In this work two different $\mathrm{Fe}_{62} \mathrm{Co}_{10} \mathrm{Y}_{8} \mathrm{~B}_{20}$ and $\mathrm{Fe}_{60} \mathrm{Co}_{10} \mathrm{Y}_{9} \mathrm{Ni}_{1} \mathrm{~B}_{20}$ alloys were produced and examined according to the statement that diffusion pumping has important role in the production process. The x-ray diffractometers and static magnetic hysteresis loops were obtained for the purpose of this work.

\section{Materials and Methods}

$\mathrm{Fe}_{62} \mathrm{Co}_{10} \mathrm{Y}_{8} \mathrm{~B}_{20}$ and $\mathrm{Fe}_{60} \mathrm{Co}_{10} \mathrm{Y}_{9} \mathrm{Ni}_{1} \mathrm{~B}_{20}$ alloys were produced in multistage process. During first one ingots were produced. During second one rapidly-cooled alloy was produced. At the last step samples preparation occurred.

At the beginning all alloying components for both alloys were weighted with the accuracy to 0.0001 grams on the RADWAG AS.110R2 analytic balance. All constituents have purity at least $99,9 \%$. Alloying elements, for each alloy separately, are placed on water-cooled copper plate inside dedicated pocket. Such copper plate is mounted inside working chamber. When alloying elements are carefully placed chamber is closed. Then is pumped to obtain high vacuum inside. Here is the difference. For $\mathrm{Fe}_{62} \mathrm{Co}_{10} \mathrm{Y}_{8} \mathrm{~B}_{20}$ alloy simple vacuum pump is used while for $\mathrm{Fe}_{60} \mathrm{Co}_{10} \mathrm{Y}_{9} \mathrm{Ni}_{1} \mathrm{~B}_{20}$ alloy not only vacuum pump is used but also diffusion pump is used to obtain better vacuum. Nevertheless, for both alloys further steps are common. Working chamber is rinsed not less than three times with argon. After each rinsing is pumped again (the difference is whether or not diffusion pump is used). Vacuum or higher vacuum together with rinsing of chamber allow to obtain ingots with assumed quality (higher with presence of greater vacuum). Pre-melting of pure titanium inside chamber seconds before melting alloying components increase purity of produced ingot. The key role of pure titanium placed inside chamber is to absorb remaining impurities imprisoned within working volume. Constituents are melted initially to obtain ingot form. Standard procedure assumes that to obtain high quality ingots it is necessary to re-melt them at least four times (two times per side). Between each reverse titanium must be re-melted. As the result of re-melting produced ingots should be well-mixed. The homogeneity of ingots is important taking into consideration their reproducibility while considering production of rapidly-cooled materials.

In the next stage ingots are cleaned at first mechanically and then via ultrasonic cleaner. Then they are divided into smaller parts to produce rods. Rods in this case are produced by the use of injection method. In this method rapidly-cooled alloy is produced within the cooling rate of $10^{-1}$ to $10^{3} \mathrm{~K} / \mathrm{s}$. Batch is placed inside quartz crucible ended with hole about $1 \mathrm{~mm}$ diameter. Crucible is located within the volume of working chamber. Please notice that the batch is at the level where copper coil is installed. Batch is melted via eddy current. Batch is injected to watercooled copper mold with suitably selected argon pressure. To be sure that alloy still will have high purity whole process is done under protective atmosphere of argon. Protective atmosphere is produced by pumping chamber by the use of chamber's pumping control block (Fig. 1) in appropriate order. To be sure that chamber has sufficient cleanness to conduct the process at least one rinsing is done. 


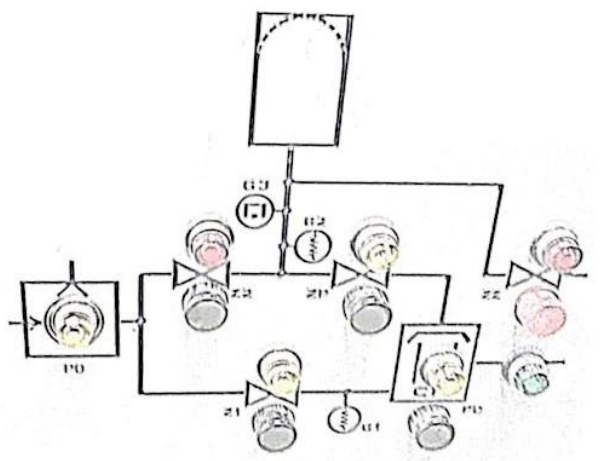

Fig. 1. Schematic representation of injection method device chamber's pumping control block

In the last step produced in injection method rods are carefully selected. Selected rods thus are mechanically cleaned as well as in ultrasonic cleaner. After cleaning inside mortar crucible rods are subjected to low energy milling.

\section{Results and Discussions}

$\mathrm{Fe}_{62} \mathrm{Co}_{10} \mathrm{Y}_{8} \mathrm{~B}_{20}$ and $\mathrm{Fe}_{60} \mathrm{Co}_{10} \mathrm{Y}_{9} \mathrm{Ni}_{1} \mathrm{~B}_{20}$ alloys were produced by following the steps described in section Materials and Methods. To remind at the step of ingot preparation $\mathrm{Fe}_{62} \mathrm{Co}_{10} \mathrm{Y}_{8} \mathrm{~B}_{20}$ alloy was produced without use of diffusion pump while in production of $\mathrm{Fe}_{60} \mathrm{Co}_{10} \mathrm{Y}_{9} \mathrm{Ni}_{1} \mathrm{~B}_{20}$ such pump was in use.

Figure 2. on the basis of $\mathrm{Fe}_{60} \mathrm{Co}_{10} \mathrm{Y}_{9} \mathrm{Ni}_{1} \mathrm{~B}_{20}$ alloy provides preview of pre-cleaned produced ingot as well as rod form rapidly-cooled alloy. Some of details might be not visible or similar to other alloys due to specification of artificial lighting used during taking the photograph.

\section{a)}

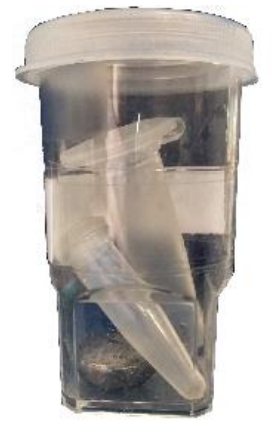

b)

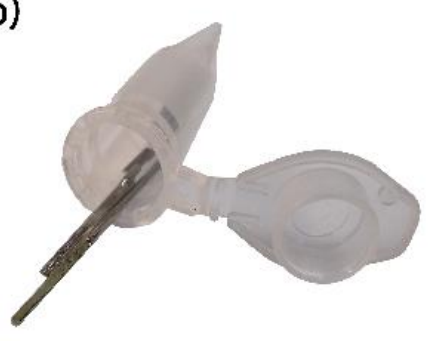

Fig. 2. Example provided on basis of $\mathrm{Fe}_{60} \mathrm{Co}_{10} \mathrm{Y}_{9} \mathrm{Ni}_{1} \mathrm{~B}_{20}$ of: a) pre-cleaned ingot in container, b) rod form rapidly-cooled alloy

Cleaning process described in section Materials and Methods is responsible for removing all surface impurities which may affect analysed samples. After cleaning samples were subjected to analysis.

To obtain x-ray diffractometer powdered alloys sample were used and analysed in BRUKER D8 ADVANCE apparatus operating in the Bragg-Brentano $(\mathrm{CuK} \alpha)$ geometry. Please notice that it is important to analyse samples as soon as possible after powder is produced. To obtain static magnetic hysteresis loops for tested alloys rod shape alloys were used. Selected samples were analysed by the device LakeShore 7307 Vibrating Sample Magnetometer. Results are presented on Fig. 3. and Fig. 4. 
The x-ray diffraction pattern, presented in Fig. 3. a) consist only of one broad maximum which is within the $2 \theta$ angle range near 40 to $50^{\circ}$. There is presence of background with low intensity with higher range of this pattern. There are small peaks in the amorphous halo that might suggest that small amount of crystalline phase is formed and should be checked if there is any match in dedicated software. Second x-ray diffraction pattern, presented in Fig. 3. b) consist also only of one broad maximum which is similarly to first one within the $2 \theta$ angle range near 40 to $50^{\circ}$. With higher range of this pattern typical amorphous background is visible but with lower intensity according to sample presented in Fig. 3. a).

a)

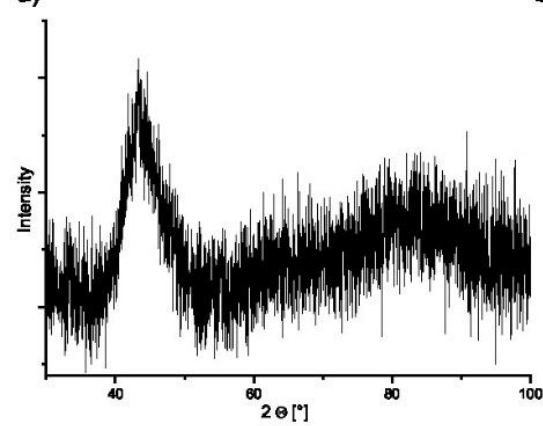

b)

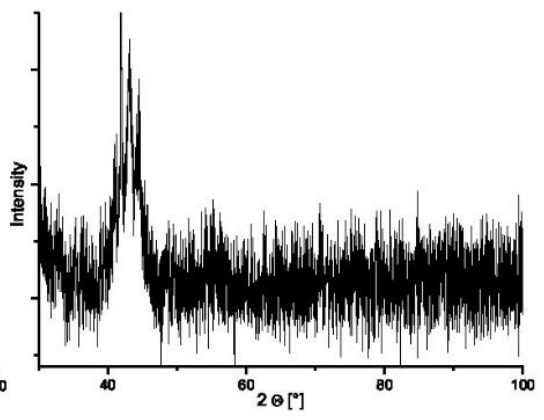

Fig. 3. Diffractometer of a) $\mathrm{Fe}_{62} \mathrm{Co}_{10} \mathrm{Y}_{8} \mathrm{~B}_{20}$ alloy without diffusion pumping at first stage of production b) $\mathrm{Fe}_{60} \mathrm{Co}_{10} \mathrm{Y}_{9} \mathrm{Ni}_{1} \mathrm{~B}_{20}$ alloy with diffusion pumping at first stage of production
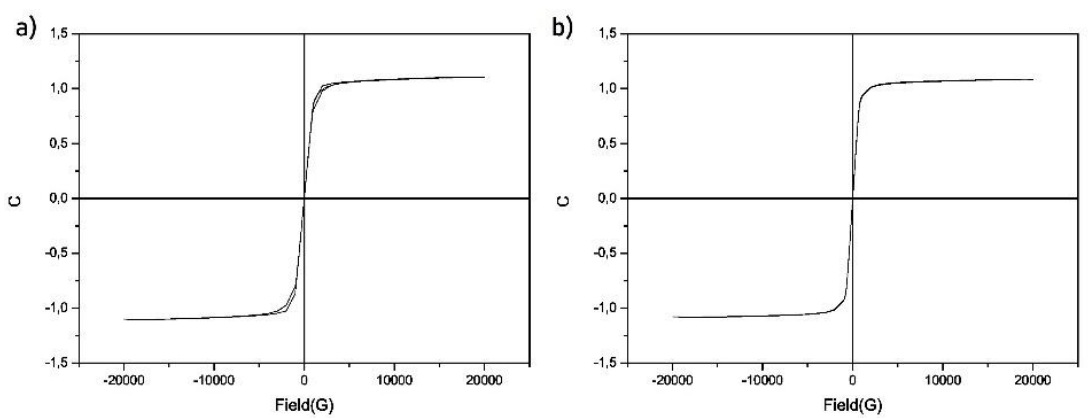

Fig. 4. Static magnetic hysteresis loops for tested alloys in solidified state: a) $\mathrm{Fe}_{62} \mathrm{Co}_{10} \mathrm{Y}_{8} \mathrm{~B}_{20}$ alloy without diffusion pumping at first stage of production $\mathrm{b}$ ) $\mathrm{Fe}_{60} \mathrm{Co}_{10} \mathrm{Y}_{9} \mathrm{Ni}_{1} \mathrm{~B}_{20}$ alloy with diffusion pumping at first stage of production

Both static magnetic hysteresis loops presented on Fig. 4. have a general shape which is typical for soft magnetic materials. The loops for the samples: a) $\mathrm{Fe}_{62} \mathrm{Co}_{10} \mathrm{Y}_{8} \mathrm{~B}_{20}$ alloy without diffusion pumping at first stage of production and b) $\mathrm{Fe}_{60} \mathrm{Co}_{10} \mathrm{Y}_{9} \mathrm{Ni}_{1} \mathrm{~B}_{20}$ alloy with diffusion pumping at first stage of production, have similar trajectories. In the case of the $\mathrm{Fe}_{62} \mathrm{Co}_{10} \mathrm{Y}_{8} \mathrm{~B}_{20}$ alloy sample the loop is slightly more deflected in the direction of the Field(G) axis, which states that the process of magnetising this alloy is relatively difficult. Values of $\mathrm{M}_{\mathrm{S}}$ saturation magnetisation and $\mathrm{H}_{\mathrm{C}}$ coercive field might be measured from the course of the loop.

\section{Conclusions}

From the results it is visible that properties depending of alloy composition. However, process of preparation has also important role according to obtained results. From the diffractometer it is visible that is high probability that use or not the diffusion pump at the first stage of production may have great important according to obtain pure amorphous alloy. For 
both diffractograms it is visible that both alloys should be considered as amorphous and from static magnetic hysteresis loops is visible that both are soft magnetic materials and may be applied in fields where such materials are applicable. It can be state that is great potential to continue work with these two alloys on many fields, e.g.: check values of $\mathrm{M}_{\mathrm{S}}$ saturation magnetisation and $\mathrm{H}_{\mathrm{C}}$ coercive field, determine Curie temperature. There is also potential of heat treatment of presented alloy to obtain controlled partial crystallisation. As the fact that during production small difference between alloys occurs is also be reasonable to do opposite production process for each alloys and then compare all results in wider range work, to obtain even greater support for statement that diffusion pumping in production process has great importance. Is recommended also to provide doubled production and test to eliminate random disturbing factors.

\section{References}

[1] W. Klement, R.H. Willens, P. Duwez, Non-crystalline Structure in Solidified Gold-Silicon Alloys, Nature 187 (4740), 1960, pp. 869-870.

[2] H.S. Chen, D. Turnbull, Formation, stability and structure of palladium-silicon based alloy glasses, Acta Metallurgica 17, 1969, pp. 1021-1031.

[3] A. Takeuchi, A. Inoue, Classification of Bulk Metallic Glasses by Atomic Size Difference, Heat of Mixing and Period of Constituent Elements and Its Application to Characterization of the Main Alloying Element, Material Transactions 46, 2005, pp. 2817-2829.

[4] T. Nagase, M. Suzuki, T. Tanaka, Formation of amorphous phase with crystalline globules in $\mathrm{Fe}-\mathrm{Cu}-\mathrm{Si}-\mathrm{B}$ and $\mathrm{Fe}-\mathrm{Cu}-\mathrm{Zr}-\mathrm{B}$ immiscible alloys, Intermetallics 61, 2015, pp. 56-65.

[5] M. E. Mchenry, M. A. Willard, D.E. Laughlin, Amorphous and nanocrystalline materials for applications as soft magnets, Progress in Materials Science 44, 1999, pp. 291-433.

[6] J. Gondro, K. Błoch, M. Nabiałek, S Garus, Influence of structural defects on the magnetic properties of massive amorphous $\mathrm{Fe}_{60} \mathrm{Co}_{10} \mathrm{Mo}_{2} \mathrm{~W}_{x} Y_{8} \mathrm{~B}_{20-x}(x=1,2)$ alloys produced with the injection casting method, Materiali in Tehnologije 50(4), 2016, pp. 559-564.

[7] M. Nabiałek, S. Walters, P. Vizureanu, M.M.A.B. Abdullah, B. Jeż, Influence of Co and Zr Content on Creation of Crystalline Phases in Rapidly-Cooled, Injection-Cast Alloys Fe $70 Z$ Zr8${ }_{x} \mathrm{Co}_{x} \mathrm{Nb}_{2} \mathrm{~B}_{20}$ (where $x=0,2,4,6$ or 8 ), ACTA PHYSICA POLONICA A 138(2), 2020, pp. 152-155.

[8] M. Nabiałek, B. Jeż, K. Jeż, K. Błoch, Structural and Magnetic Properties of the Rapid Cooled Alloys: Fe60Co10Y5+xZr5-xB20 (Where: $x=0$ or 2), Revista de Chimie 70(1), 2019, pp. 224-227.

[9] M. Nabiałek, B. Jeż, K. Błoch, The Influence of the Silicon Content on the Formation of Fe23B6 Metastable Phases in $\mathrm{Fe}_{65} \mathrm{Co}_{11-x} \mathrm{~B}_{20} \mathrm{Si}_{x} \mathrm{Zr}_{2} \mathrm{Hf}_{2}$ Bulk Amorphous Alloys, METALLURGICAL AND MATERIALS TRANSACTIONS A 51, 2020, pp. 46024609.

[10] J. Gondro, K. Błoch, M. Nabiałek, Structure and Magnetic Properties of Amorphous $\mathrm{Fe}_{82} \mathrm{Zr}_{7} \mathrm{Nb}_{2} \mathrm{Cu}_{1} \mathrm{~B}_{8}$ and Crystalline $\mathrm{Fe}_{82} \mathrm{Zr}_{6} \mathrm{Y}_{1} \mathrm{Nb}_{2} \mathrm{Cu}_{1} \mathrm{~B}_{8}$ Alloys, ACTA PHYSICA POLONICA A 130, 2016, pp. 909-912.

Received: January 28, 2021

Accepted: March 01, 2021 